\title{
DIREITO INTERNACIONAL E POLUIÇÃO SONORA MARINHA: EFEITOS JURÍDICOS DO RECONHECIMENTO DO SOM COMO FONTE DE POLUIÇÃO DOS OCEANOS
}

Diego de Alencar Salazar Primo

Mestrando em Direito pela Universidade Federal do Ceará (UFC). Advogado. Pesquisador do grupo de pesquisa Ecomplex - Direito, Complexidade e Meio Ambiente, da UNI7. Email: dasp55@gmail.com

\section{Cecília Perdigão Barreto}

Oceanógrafa e Mestre em Ciências Marinhas Tropicais, área de poluição marinha, pela UFC. Graduanda em Direito pela UFC. Pesquisadora do grupo de pesquisa em Direito e Assuntos Internacionais (GEDAI) e do Verde Luz. Email: ceciliacpb@gmail.com

Tarin Frota Mont Alverne

Doutorado em Direito Internacional do Meio Ambiente - Université de Paris V e Universidade de São Paulo; Mestrado em Direito Internacional Público - Université de Paris; Professora da Faculdade de Direito da Universidade Federal do Ceara (UFC).

Email: tarinfmontalverne@yahoo.com.br

\section{RESUMO}

Apesar da gravidade e da clara natureza internacional do problema, não existe, até este momento, nenhum acordo global ou regional que trate especificamente do combate aos efeitos deletérios da emissão de ruídos antropogênicos nos oceanos. O objetivo deste artigo é investigar em que medida essas emissões podem configurar poluição marinha, nos termos da Convenção das Nações Unidas sobre Direito do Mar (CNUDM), e que repercussões práticas isso acarreta, do ponto de vista do regime jurídico aplicável a essas atividades. Desenvolve-se, para tanto, pesquisa aplicada, de natureza teórica e finalidade descritiva e explicativa, com abordagem qualitativa e raciocínio dedutivo e sistêmico, mediante análise de fontes documentais e bibliográficas. Conclui-se que a poluição sonora preenche todos os requisitos da definição de poluição marinha da CNUDM, pelo que as disposições desse tratado acerca da poluição marinha e da proteção do meio ambiente marinho são plenamente aplicáveis à emissão antropogênica de ruídos nos oceanos. Verifica-se, ademais, que existem diversos outros 
instrumentos jurídicos internacionais aplicáveis à poluição sonora marinha, pelo que a hipótese de um vazio normativo sobre o tema resta afastada, havendo, assim, de se pensar em outras causas do recrudescimento dessa espécie de poluição, a fim de que ela possa ser eficientemente combatida.

Palavras-chave: Direito Internacional; Poluição marinha; Poluição sonora marinha; Regime jurídico.

INTERNATIONAL LAW AND OCEAN NOISE POLLUTION: LEGAL EFFECTS OF THE RECOGNITION OF SOUND AS A SOURCE OF OCEAN POLLUTION

\section{ABSTRACT}

Despite the seriousness and clear international nature of the problem, there is no global or regional agreement which specifically addresses the deleterious effects of anthropogenic noise in the oceans. The purpose of this article is to investigate the extent to which such emissions may constitute marine pollution under the United Nations Convention on the Law of the Sea (UNCLOS), and what practical implications this entails from the point of view of the legal regime applicable to such activities. For this purpose, an applied research, of theoretical nature and descriptive and explanatory purposes, with a qualitative approach and deductive and systemic reasoning, is carried out, through the analysis of documentary and bibliographic sources. The article concludes that noise pollution fulfills all the requirements of the UNCLOS definition of marine pollution and, therefore, the provisions of that treaty on marine pollution and protection of the marine environment are fully applicable to the anthropogenic emission of noise in the oceans. In addition, there are several other international legal instruments applicable to marine noise pollution, which rules out the hypothesis of a normative void on the subject and highlights the need to think about other causes of the increase of this type of pollution, so that it can be efficiently addressed.

Keywords: International Law; Marine pollution; Ocean noise pollution; Legal regime. 


\section{INTRODUÇÃO}

Os efeitos nocivos da emissão de ruídos antropogênicos nos oceanos, outrora ignorados, ocupam hoje papel de destaque entre as preocupações da sociedade internacional. O tema constituiu, inclusive, pauta de debate na Conferência dos Oceanos, evento mundial destinado à promoção do desenvolvimento sustentável no âmbito dos mares e oceanos, realizado sob os auspícios da ONU, em junho de 2017, em Nova Iorque (ONU, 2017).

A intensificação do uso e da exploração do mar em uma escala global - já se fala mesmo em uma "industrialização dos oceanos" (STOCKER, 2016) - acarreta o recrudescimento dos ruídos emitidos, dentre várias outras fontes, pelo tráfego de navios, pela prospecção e extração de gás e petróleo e por sonares militares, o que causa impactos negativos na biota marinha.

Afora os incontornáveis dilemas de ética animal envolvidos quando se trata de atividades humanas que causem sofrimento, dor e mesmo morte a seres vivos, a emissão antropogênica de som nos oceanos produz, ainda, alterações significativas nas complexas redes ecossistêmicas marinhas, inclusive no que tange às cadeias alimentares, o que afeta gravemente o equilíbrio ecológico essencial não apenas à conservação da biodiversidade marinha, mas também ao bem-estar e à sadia qualidade de vida dos próprios seres humanos.

De fato, prejuízos ambientais causados ao meio ambiente marinho frequentemente resvalam, por ricochete, no patrimônio humano, podendo-se cogitar, por exemplo, sobre danos ambientais reflexos à saúde e à alimentação humanas, direitos humanos estatuídos no art. 25 da Declaração Universal dos Direitos Humanos, em prejuízo do direito a uma vida saudável, garantido, dentre outros, pelo art. $1^{\circ}$ da Declaração do Rio sobre Meio Ambiente e Desenvolvimento, de 1992.

Pode-se destacar, ainda, a consumação de prejuízos de ordem econômica, ante a afetação das cadeias alimentares e a consequente escassez de seres vivos marinhos com importância comercial, bem como os danos diretos aos seres humanos, como as agressões acústicas a mergulhadores em áreas marinhas utilizadas para turismo ou recreação (MCCARTHY, 2001).

Apesar da gravidade do tema, o tratado internacional mais importante em matéria de Direito do Mar, a Convenção das Nações 
Unidas sobre Direito do Mar (CNUDM), de 1982, não o abordou de forma expressa. Tampouco existe qualquer outro tratado ou documento normativo de espectro global que discipline, de forma clara e específica, a questão dos impactos ambientais da emissão de ruídos antropogênicos nos oceanos.

Essa ausência de específica normatização global do assunto é ainda mais preocupante diante do fato de que a maior parte dos oceanos é composta por águas internacionais (FAO, 2017), situadas além da jurisdição dos Estados, as quais também estão sujeitas aos efeitos nocivos dos ruídos antropogênicos.

Nessas regiões, afora as dificuldades de fiscalização e proteção decorrentes da própria extensão geográfica, há o agravante de que os esforços meramente individuais são de pouca utilidade no combate à poluição sonora marinha e na garantia de efetiva proteção acústica dos recursos vivos, o que reclama, assim, uma atuação enérgica por parte do Direito Internacional.

Diante desse quadro, indaga-se se os efeitos nocivos da emissão antropogênica de ruídos nos oceanos podem-se amoldar à definição de poluição marinha trazida pela CNUDM e, em caso positivo, que repercussões práticas isso traria do ponto de vista da proteção jurídica (arcabouço normativo internacional) do meio ambiente marinho contra danos ambientais de natureza acústica. O presente artigo dedica-se a responder a esses questionamentos.

Além da premência do assunto, da ausência de expressa disciplina normativa global e da potencialidade lesiva gerada pelo desconhecimento do tema, que levam à omissão no enfrentamento do problema, a pesquisa justifica-se, ainda, em virtude da sua inovação no âmbito do Direito brasileiro, considerando que a literatura jurídica nacional tem dispensado pouca atenção ao assunto.

A presente pesquisa é do tipo aplicada, tem natureza teórica e finalidade descritiva e explicativa. A abordagem empregada é a qualitativa, com predomínio de fontes documentais e bibliográficas. O raciocínio é eminentemente sistêmico e dedutivo, orientando-se pelo paradigma epistemológico da complexidade.

$\mathrm{Na}$ tentativa de resposta adequada ao problema e de consecução do objetivo central, optou-se por dividir o trabalho em quatro partes principais. Inicialmente, avalia-se o que a CNUDM entende por poluição marinha e como ela disciplina esse assunto. Em seguida, analisam-se a natureza e os efeitos decorrentes das emissões antropogênicas de ruídos no 
meio ambiente marinho, demonstrando-se que elas podem legitimamente ser consideradas como "poluição marinha" pelo Direito Internacional. No terceiro tópico, a partir da exposição do tópico anterior, discorre-se acerca do arcabouço jurídico-normativo internacional aplicável à emissão antropogênica de ruídos nos oceanos, como forma de proteger o meio ambiente marinho. Ao final, apresentam-se as conclusões da pesquisa.

\section{A ABRANGÊNCIA DO CONCEITO JURÍDICO DE POLUIÇÃO DO MEIO MARINHO: A PROBLEMÁTICA DA POLUIÇÃO SONORA MARINHA}

Em cumprimento ao item 36 do Plano de Implementação da Conferência Mundial sobre Desenvolvimento Sustentável, ocorrida em Joanesburgo, em 2002 (ONU, 2002), e na esteira do que prevê a Meta 14 da Agenda 2030 para o Desenvolvimento Sustentável (ASSEMBLEIA GERAL DA ONU, 2015), foi elaborada, em dezembro de 2015, sob os auspícios da Assembleia Geral da ONU, a Primeira Avaliação Marinha Global Integrada - Avaliação Mundial dos Oceanos I, com a colaboração de centenas de especialistas de diversos países.

Essa avaliação teve a finalidade de produzir e divulgar conhecimentos técnico-científicos sobre os oceanos, de modo a permitir uma maior compreensão dos benefícios que os oceanos proporcionam à humanidade e dos impactos humanos provocados nos oceanos (ONU, 2015), assegurando a conservação e o uso sustentável dos oceanos, dos mares e dos recursos marinhos.

O relatório compilado da primeira Avaliação Mundial dos Oceanos (ONU, 2015) pontua que o barulho antropogênico nos oceanos cresceu na última metade do século XX. A maior parte dos ruídos provém de embarcações comerciais, que produzem sons na mesma faixa de frequência usada por muitos mamíferos marinhos para comunicação. Por se tratar de frequências baixas, os ruídos provocados por navios são capazes de se propagar eficientemente no mar, afetando a biota marinha situada a longas distâncias do emissor.

Outras fontes significativas de ruídos nos oceanos, segundo o relatório, são a exploração sísmica pela indústria de hidrocarbonetos offshore, bem como os sonares. A instalação de cabos submarinos e de equipamentos de energia renovável offshore, assim como projetos de dragagem, embora em menor grau, também podem emitir ruídos 
subaquáticos potencialmente danosos.

Registrou-se ainda que, embora muito esteja sendo feito para reduzir as emissões sonoras oriundas de embarcações, não se dedica muita atenção às rotas percorridas pelos navios, tampouco aos efeitos dessas rotas em termos de barulho.

Por outro lado, verifica-se que grande parte dos estudos sobre os impactos adversos da emissão antropogênica de ruídos nos oceanos voltase aos mamíferos marinhos (DOTINGA; ELFERINK, 2000), notadamente aos cetáceos, mas o relatório da ONU informa que esses impactos, conforme se verificou em trabalhos científicos, afetam pelo menos 55 espécies marinhas, incluindo peixes, tartarugas marinhas e invertebrados.

Esses fatos dão conta da gravidade e complexidade do problema e levantam questionamentos sobre a atuação do Direito Internacional na sua regulação. Segundo Dotinga e Elferink (2000), a questão da emissão antropogênica de som no ambiente marinho é tipicamente de interesse do Direito Internacional, porque: a) muitas atividades marinhas geradoras de barulho no ambiente marinho são internacionais ou transfronteiriças por natureza, como a navegação; b) a competência de um Estado para adotar medidas que disciplinem a emissão de sons nos oceanos é circunscrita pelo Direito Internacional; c) atividades que produzem ruídos nos oceanos são frequentemente praticadas em áreas situadas além da jurisdição dos Estados (águas internacionais) ou sujeitas à jurisdição de mais de um Estado; d) a propagação do som nos oceanos pode ter caráter transfronteiriço; e) a poluição sonora marinha pode afetar espécies migratórias, que vivem temporariamente em áreas sujeitas à jurisdição de Estados distintos situadas além da jurisdição dos Estados.

Por constituir um assunto de interesse internacional e de repercussões prejudiciais ao meio ambiente marinho e aos seres humanos, a poluição marinha tem, ao longo dos anos, recebido atenção do Direito Internacional.

A Convenção das Nações Unidas sobre o Direito do Mar (CNUDM), tratado internacional celebrado em Montego Bay, em 1982, cuja amplitude e densidade renderam-lhe a alcunha de "Constituição do Mar", é o principal documento jurídico internacional a normatizar, de forma abrangente, a questão da poluição marinha, abordando diversas de suas fontes de maneira específica e detalhada, a exemplo da poluição de origem telúrica, da poluição por alijamento, da poluição proveniente de embarcações e da poluição proveniente da atmosfera ou através dela. 
As disposições da CNUDM sobre poluição marinha chegam a constituir, na visão de alguns, um dos aspectos mais salutares desse tratado, nos quais futuros acordos internacionais regulamentadores devem buscar alicerce (GJERDE, 2012). A CNUDM constitui um exemplo de tratado umbrela (SCALASSARA, 2008), isto é, um "tratado guarda-chuva", que estabelece regras gerais, com base nas quais podem ser celebrados outros atos internacionais menos solenes e/ou mais específicos, a fim de complementar as suas disposições e garantir-lhes maior efetividade.

Ao traçar essa moldura, o advento da CNUDM representou a primeira vez em que um tratado internacional englobou todas as formas de poluição marinha (GJERDE, 2012), impondo aos Estados o dever de adotar medidas necessárias à prevenção, redução e controle da poluição do meio marinho, qualquer que seja a sua fonte, além de harmonizar as suas políticas a esse respeito (ONU, 1982).

Sabe-se que a CNUDM, assim como qualquer outro texto legal, é um produto de seu tempo, de modo que sempre estará ligada à época em que foi negociada e adotada (SCOVAZZI, 2016), isto é, o período de 1973 a 1982. Não obstante, isso não impediu que ela antevisse a possibilidade de serem criadas novas formas de poluição e impusesse aos Estados, no art. 196, os mesmos deveres de prevenção, redução e controle da poluição "resultante da utilização de tecnologias sob sua jurisdição ou controle" (ONU, 1982).

Essa previsão há de ser lida à luz da percuciente definição de "poluição do meio marinho" que a CNUDM trouxe em seu pórtico, tomando para si, em prol da segurança jurídica, uma definição que, tipicamente, caberia à doutrina. Dispõe o art. $1^{\circ}, 4$, da CNUDM:

\section{ARTIGO 1 \\ Termos utilizados e âmbito de aplicação}

1. Para efeitos da presente Convenção:

\section{$[\ldots]$}

4) "poluição do meio marinho" significa a introdução pelo homem, direta ou indiretamente, de substâncias ou de energia no meio marinho, incluindo os estuários, sempre que a mesma provoque ou possa vir provocar efeitos nocivos, tais como danos aos recursos vivos e à vida marinha, riscos à saúde do homem, entrave às atividades 
marítimas, incluindo a pesca e as outras utilizações legítimas do mar, alteração da qualidade da água do mar, no que se refere à sua utilização, e deterioração dos locais de recreio;

Ao trazer uma definição legal de poluição do meio marinho, sem restringi-la às fontes de poluição conhecidas à época de sua negociação, a CNUDM elasteceu a sua própria efetividade, na medida em que dotou as suas disposições sobre combate à poluição de uma atualidade ad futurum, imune à obsolescência que costuma caracterizar os textos jurídicos, os quais não conseguem acompanhar, à mesma velocidade, as mudanças sociais e os efeitos perniciosos do desenvolvimento humano, que reclamam resposta do Direito.

Com efeito, o art. 196 dispõe sobre novas formas de poluição que venham a resultar do uso de tecnologias (não especificadas), e o art. $1^{\circ}, 1,4$, caracteriza como poluição a introdução pelo homem de quaisquer substâncias ou de energia no meio marinho, sempre que estas provoquem ou venham a provocar efeitos nocivos.

A chamada poluição sonora marinha não encontra previsão expressa na CNUDM. Estaria ela, porém, abrangida pelo conceito jurídico de poluição do meio marinho? Vale dizer: a emissão antropogênica de ruídos nos oceanos configura "substância" ou "energia" capaz de provocar efeitos nocivos no meio ambiente marinho?

\section{POLUIÇÃO SONORA MARINHA: RISCO POTENCIAL AO ECOSSISTEMA MARINHO}

A resposta à pergunta formulada ao final do tópico anterior pressupõe exame individualizado das duas variáveis da fórmula jurídica para caracterização de uma atividade, ação ou fenômeno como "poluição marinha", nos termos da CNUDM: a) introdução de substância ou energia; b) potencialidade ou efetiva produção de efeitos nocivos.

\subsection{O som como energia: preenchimento do primeiro requisito do art. $1,1,4$, da CNUDM}

O ambiente marinho não é naturalmente silencioso. Desde 1900, ruídos naturais dos oceanos já foram relatados como interferentes na comunicação acústica submarina de navios de marinha (NEO et al., 
2014). Fenômenos como tempestades, ventos, terremotos e ondas, por exemplo, produzem sons que, juntamente com os sons emitidos pela fauna, constituem o nível natural de background sonoro dos oceanos. Este nível de background corresponde aos sons de origem natural que estão presentes de forma constante no meio subaquático, ao qual os organismos marinhos estão adaptados (MERCHANT et al., 2015).

Contudo, após a intensificação dos processos industriais de larga escala, do crescimento populacional e da globalização dos sistemas de transporte, houve introdução maciça de ruídos de origem antropogênica no ambiente marinho, comprometendo o balanço sonoro deste ecossistema (SHANNON et al., 2016; MERCHANT et al., 2015). Como consequência, os animais marinhos passaram a ser expostos aos diversos impactos dos ruídos provenientes de atividades como navegação, exploração de petróleo e gás, construções offshore e utilização de sonares, por exemplo, em escalas locais e regionais (MERCHANT et al., 2015).

Os ruídos oriundos de atividades humanas passaram a ser vistos como potenciais ameaças aos animais marinhos recentemente, quando se descobriu, na década de 1970, a importância do som para baleias da subordem Mysticeti. A partir daí, nos anos 1980 e 1990, a poluição sonora marinha passou a ser encarada pela comunidade científica como um problema ambiental que necessitava de meios de controle (WILLIAMS et al., 2015; SIMMONDS et al., 2014).

Se se considerar apenas aspectos físicos, não há diferença entre som e ruído. Contudo, usualmente, som é considerado uma percepção sensorial de interesse, associado a sensações prazerosas, enquanto que ruído é um som indesejado, uma perturbação injustificada dentro de uma banda sonora de frequência útil (CONCHA-BARRIENTOS; CAMPBELLLENDRUM; STEENLAND, 2004). Desta maneira, a poluição sonora marinha é a resultante da introdução artificial de ruídos nos oceanos, provocando impactos aos organismos marinhos sensíveis.

A Comissão para Mamíferos Marinhos dos Estados Unidos (MMC, em inglês), em relatório publicado em 2007, definiu o som como energia que se manifesta como uma vibração ou onda acústica através de um meio sólido, líquido ou gasoso, sendo caracterizada por parâmetros diversos, como pressão sonora e intensidade. Ruídos, por sua vez, foram definidos por Zajarkiewicch (2010) como emissões de energia oriundas de fenômenos vibratórios que causam perturbação quando captados pelo sistema auditivo. Sons e ruídos são, portanto, energia. 
Desta maneira, parece claro que a emissão de ruídos por atividades antrópicas, que são percebidos por organismos aquáticos, encaixa-se na definição de poluição marinha prevista no artigo $1^{\circ}$ da Convenção das Nações Unidas sobre o Direito do Mar (CNUDM), pelo menos quanto ao seu primeiro requisito.

\subsection{Evidências científicas dos impactos ambientais negativos causados por emissões antropogênicas de ruídos no meio ambiente marinho}

Ruídos subaquáticos de origem antropogênica têm sido considerados como um problema de escala global, que impactam animais marinhos de táxons variados, incluindo vertebrados, como mamíferos e peixes, e invertebrados, como moluscos e crustáceos (WILLIAMS et al., 2015). Estes impactos ocorrem porque muitos organismos necessitam do som para comunicação entre seres da mesma espécie, para navegação e para a detecção de presas, por exemplo (MERCHANT et al., 2015). Ao afetar organismos tão distintos, a poluição marinha constitui um risco para a saúde do ecossistema marinho como um todo.

Diversos estudos científicos relatam que alterações no padrão acústico dos oceanos têm sido capazes de provocar alterações no desenvolvimento, comportamento, fisiologia e distribuição espacial da fauna marinha (MERCHANT et al., 2015). Contudo, quantificar os efeitos da poluição sonora sobre os animais marinhos é uma tarefa árdua. Isto porque a sensibilidade ao ruído antropogênico varia de espécie para espécie e, dentro de uma mesma espécie, depende de fatores como sexo, idade e condições em que o animal se encontra. Ademais, a poluição sonora pode induzir nos organismos respostas biológicas associadas, como alteração no padrão de vocalização, redução e mudança de habitat, que são alterações comportamentais difíceis de se atribuir apenas a este tipo de poluição (SHANNON et al., 2016; VOELLMY et al., 2014).

Além dos impactos comportamentais frutos do estresse fisiológico gerado pela introdução de ruídos antropogênicos nos oceanos, danos físicos a estruturas auditivas, perda da capacidade de audição e até mesmo morte de organismos expostos a ruídos de alta intensidade são relatados na literatura científica (SIMMONDS et al., 2014).

Mamíferos marinhos, especialmente os cetáceos, são os animais mais impactados pela poluição sonora, porque o som exerce papel fundamental na vida destes seres, uma vez que está relacionado a uma gama 
de comportamentos necessários à sua existência. A introdução artificial de ruídos nos oceanos é capaz de interferir na recepção de sinais acústicos por estes animais, num fenômeno conhecido como mascaramento acústico (ERBE et al., 2016).

O mascaramento acústico ocorre quando sons de interesse não conseguem ser detectados apropriadamente pelo aparelho auditivo dos animais marinhos, por terem sido sobrepostos por ruídos indesejados de frequência similar (ERBE et al., 2016). Ruídos de baixa frequência são os maiores responsáveis por este tipo de interferência, refletindo em deficiências na socialização, na coesão do grupo, na comunicação, na alimentação, alterações no padrão natatório e no reconhecimento entre mãe e filhote de cetáceos (ERBE et al., 2016). A poluição sonora também é capaz de reduzir a frequência de canto de baleias, mecanismo necessário para o sucesso reprodutivo dos machos. Este tipo de impacto é capaz de gerar efeitos negativos na reprodução de indivíduos e na manutenção de populações inteiras de baleias, como a jubarte (CERCHIO et al., 2014).

Apesar da predominância de pesquisas sobre as perturbações causadas pela introdução de ruídos artificiais em mamíferos marinhos, é sabido que outros animais, como peixes, são também impactados, apesar de ainda existirem vácuos de conhecimento que impeçam a plena compreensão e análise da dimensão dos impactos nestes organismos Por exemplo, a análise dos efeitos da poluição sonora foi feita em apenas uma fração das mais de 32.000 espécies de peixes conhecidas atualmente (HAWKINGS; PEMBROKE; POPPINS, 2015).

Apesar de nem todos os peixes captarem sons da mesma forma, fontes de ruídos de alta intensidade podem lhes causar danos graves, como danos aos tecidos do sistema auditivo, e danos temporários de audição, no caso dos peixes dotados de ouvido interno, aumento da taxa de batimentos cardíacos e respostas do sistema endócrino ao estresse (NEO et al., 2014; SMITH, 2004). Estas respostas negativas podem refletir nas taxas de crescimento, de reprodução e, em último caso, na sobrevivência de espécies (SLABEKOORN et al., 2010), o que, evidentemente, pode influenciar na disponibilidade de recursos pesqueiros, para fins de consumo humano.

Diversos outros estudos científicos têm sido realizados em relação a outros componentes da fauna marinha, havendo, assim, considerável quantidade de evidências que apontam para a produção de efeitos nocivos, a partir da emissão antropogênica de ruídos. Os danos de origem acústica causados a seres vivos marinhos preenchem, assim, o segundo requisito da 
CNUDM para caracterização de uma atividade como poluição marinha, de modo que se torna possível, pois, falar-se em poluição sonora marinha, modalidade de poluição marinha abrangida pelo art. $1^{\circ}, 1$, 4, da CNUDM.

\section{REGIME JURÍDICO INTERNACIONAL DA POLUIÇÃO SONORA MARINHA: HÁ UMA LACUNA NORMATIVA?}

Apesar da clara natureza internacional do problema, não há, até o presente momento, no plano internacional, nenhum acordo global ou regional que trate especificamente do som subaquático, tampouco de seus impactos em mamíferos marinhos (FIRESTONE; JARVIS, 2007) que, como se viu, são os animais marinhos em relação aos quais há mais estudos referentes a impactos causados pela poluição sonora.

Não obstante, viu-se que as emissões antropogênicas de ruídos subaquáticos podem qualificar-se juridicamente como poluição marinha, de acordo com a definição trazida pela CNUDM, uma vez que elas são uma forma de energia e provocam efeitos nocivos, como danos aos recursos vivos e à vida marinha como um todo. Diante disso, não há dúvidas de que as disposições da Convenção do Mar sobre poluição marinha e sobre proteção do meio ambiente marinho aplicam-se à poluição sonora nos oceanos (FIRESTONE; JARVIS, 2007).

Por conta disso, é dever dos Estados proteger e preservar o meio marinho dos efeitos deletérios dos ruídos antropogênicos (art. 192 da CNUDM) e tomar medidas para prevenir, reduzir e controlar a poluição sonora marinha, além de se abster de causar prejuízos por poluição sonora a outros Estados e ao seu meio ambiente (art. 194, 1 e 2, da CNUDM).

Têm ainda os Estados a obrigação de proteger e preservar os ecossistemas raros ou frágeis, bem como o habitat de espécies e outras formas de vida marinha em vias de extinção, ameaçadas ou em perigo, resguardando-as dos danos que a emissão de ruídos subaquáticos possa vir a causar-lhes (art. 194, 5, da CNUDM).

Aplicam-se, ainda, à poluição sonora marinha, os deveres de proteção ambiental previstos na CNUDM quanto à realização de pesquisas científicas marinhas (FIRESTONE; JARVIS, 2007) - vide arts. 240, "d", e 263 , 3, da CNUDM -, bem como à prática de atividades nos fundos marinhos sob jurisdição nacional (art. 208) e na Área (arts. 145 e 209).

Ademais, embora não esteja positivado na CNUDM de forma expressa, é certo que os Estados devem guiar-se, inclusive em matéria de 
poluição sonora marinha, pelo princípio da precaução, que se originou no próprio Direito Internacional do Meio Ambiente (CRETELLA NETO, 2012).

Previsto em inúmeros tratados globais e regionais sobre meio ambiente, bem como em instrumentos internacionais não cogentes, em ordenamentos jurídicos nacionais e na jurisprudência nacional e internacional, o princípio da precaução, tamanha a sua influência, já vem sendo considerado por alguns como uma regra de direito costumeiro (SIRINSKIENE, 2009), fonte do Direito Internacional, segundo o art. 38 do Estatuto da Corte Internacional de Justiça (CIJ, 1945).

Na sua formulação mais aceita, prevista na Declaração do Rio, de 1992, adotada ao final da Conferência das Nações Unidas sobre Meio Ambiente e Desenvolvimento (Eco-92), o princípio da precaução prevê que "quando houver ameaça de danos graves ou irreversíveis, a ausência de certeza científica absoluta não será utilizada como razão para o adiamento de medidas economicamente viáveis para prevenir a degradação ambiental" (ONU, 1992a).

Segundo Gillespie, há uma grande quantidade de incertezas científicas em matéria de impactos da poluição sonora em espécies marinhas (GILLESPIE, 2007), as quais proporcionam um solo fértil para a aplicação do princípio da precaução, na medida em que a proteção dessas espécies não pode ficar à espera de uma certeza científica absoluta - epistemologicamente inatingível (PRIMO; OLIVEIRA, 2017), devendo, ao contrário, ser regulada antecipadamente, a fim de se evitar ou amenizar a consumação de danos.

Afora a CNUDM, existem outros instrumentos globais e regionais que podem fornecer bases jurídico-normativas para a proteção do meio ambiente marinho, no que diz respeito à emissão antropogênica de ruídos, ainda que sem relacioná-la especificamente à definição de poluição marinha contida no art. $1^{\circ}$ da Convenção de Montego Bay.

Um exemplo seria a Convenção Internacional para a Regulamentação da Pesca da Baleia, concluída em 1946. Esse tratado previu a criação da Comissão Internacional da Baleia (CIB), que se dedica, dentre outras coisas, a estudar, avaliar e difundir informações relativas aos métodos próprios à manutenção e ao incremento da espécie baleeira (ONU, 1946).

O Comitê Científico da CIB tem se dedicado, pelo menos desde 1996, ao estudo dos efeitos dos barulhos antropogênicos nas baleias, 
elaborando documentos e recomendações aos Estados, a fim de minimizar o risco de danos por poluição sonora causados em cetáceos (FIRESTONE; JARVIS, 2007), considerando que a audição é o principal sentido desses animais, que a utilizam para alimentação, migração e reprodução (INTERNATIONAL WHALING COMISSION, 2016).

Em 2014, a CIB participou de projeto internacional dedicado ao estudo e mapeamento da paisagem sonora de cetáceos, no intuito de fornecer suporte científico a gestores e agentes políticos, mediante caracterização, monitoramento e gestão dos potenciais impactos crônicos ou cumulativos de ruídos antropogênicos nesses mamíferos marinhos (INTERNATIONAL WHALING COMISSION, 2016). Mais recentemente, em 2016, a CIB elaborou estudo acerca dos impactos do "masking" ("mascaramento"), fenômeno que ocorre quando outros sons (inclusive os antropogênicos) bloqueiam ou mascaram os sons dos quais os cetáceos dependem para sobreviver (INTERNATIONAL WHALING COMISSION, 2016).

Um outro tratado internacional que pode ajudar a regular, ainda que indiretamente, o problema da poluição sonora marinha é a Convenção sobre Diversidade Biológica (CDB), de 1992, que impõe às partes o dever de adotar medidas de conservação e utilização sustentável da diversidade biológica, inclusive mediante estabelecimento de áreas protegidas, sempre a fim de evitar ou minimizar impactos negativos (ONU, 1992b).

A princípio, nada impede que as disposições da CDB sejam aplicadas em relação à poluição sonora marinha, quando esta implicar prejuízos à biodiversidade. Não obstante, como ressalta Weilgart, são poucos os estudos científicos acerca dos impactos da poluição sonora na biodiversidade marinha (WEILGART, 2008).

Também o Acordo para Implementação das Disposições da CNUDM sobre a Conservação e Ordenamento de Populações de Peixes Transzonais e de Populações de Peixes Altamente Migratórios, de 1995, pode oferecer algum suporte normativo em matéria de poluição sonora marinha, mesmo para além da pesca e das espécies de peixe por ele abordadas (FIRESTONE; JARVIS, 2007), uma vez que o seu art. 50 " "d" e “f”, impõe aos Estados que pescam em alto-mar o dever de: a) avaliar não apenas os impactos da pesca, mas também os de outras atividades humanas sobre populações-alvo "e espécies pertencentes ao mesmo ecossistema ou que dependam ou estejam associadas às populações alvo" (ONU, 1995), o que pode abranger, por exemplo, mamíferos marinhos; b) reduzir ao mínimo a poluição - e, como se viu, a emissão antropogênica de ruídos 
nos oceanos pode configurar poluição marinha - e impactos sobre espécies associadas ou dependentes, particularmente espécies ameaçadas.

A Convenção de Bonn sobre Conservação de Espécies Migratórias de Animais Selvagens também pode servir de fundamento jurídico à proteção acústica dos seres vivos marinhos, considerando-se que o seu art. III, 4, "b" e "c", impõe o dever de prevenir, remover, compensar ou minimizar, de forma apropriada, os efeitos adversos das atividades ou obstáculos que dificultem seriamente ou impeçam a migração de certas espécies migratórias, bem como, na medida do possível e apropriado, de prevenir, reduzir ou controlar os fatores que ameaçam ou possam ameaçar essas espécies (FIRESTONE; JARVIS, 2007).

Destaque-se que a Conferência das Partes da Convenção de Bonn tem sistematicamente envidado esforços no sentido de aprofundar o conhecimento científico sobre a poluição sonora marinha e de proteger as espécies altamente migratórias dos efeitos nocivos desse tipo de poluição. Na COP 12 da referida Convenção, ocorrida em 2017, deu-se prosseguimento ao projeto de elaboração e aprovação de um conjunto de diretrizes sobre avaliações de impacto ambiental para atividades geradoras de ruído nos oceanos (UNEP, 2017), o que reforça a previsão contida no artigo 206 da CNUDM, que, embora deixe aos Estados uma considerável margem de discricionariedade (ELFERINK, 2012), prevê a necessidade de avaliação de atividades potencialmente poluidoras (ONU, 1982), inclusive em termos sonoros.

Pode-se, ainda, cogitar da aplicabilidade das disposições da Convenção Internacional para a Prevenção da Poluição por Navios (MARPOL), concluída em Londres, em 2 de novembro de 1973, e de seu Protocolo, de 1978, à poluição sonora marinha. Segundo Palmer, o fato de a MARPOL limitar o conceito de poluição à liberação de "substâncias danosas" (art. $2^{\circ}$ ) permitiria concluir que a MARPOL não se aplica à liberação, por parte de navios, de energia sonora nos oceanos (PALMER, 2009).

Essa conclusão, porém, é questionável, na medida em que o som pode constituir uma substância danosa ao meio ambiente marinho, a depender da intensidade e da forma como for emitido. Aliás, o próprio Preâmbulo da MARPOL enuncia o objetivo de "obter a completa eliminação da poluição intencional do meio ambiente marinho por óleo e por outras substâncias danosas", ressaltando expressamente que "este propósito pode ser melhor atingido através da criação de regras não restritas à poluição por 
óleo, tendo um significado universal" (ONU, 1973).

De todo modo, é fato que a International Maritime Organization (IMO), órgão internacional permanente, encarregado de administrar a aplicação da MARPOL 73/78 e de promover a segurança marítima e a proteção do meio ambiente marinho, tem contribuído ativamente para a minimização do problema relacionado à poluição sonora marinha (PALMER, 2009).

Em 2014, a IMO divulgou um documento intitulado "Diretrizes para a redução do ruído subaquático da navegação comercial para enfrentar impactos adversos na vida marinha" (IMO, 2014), aplicável a qualquer embarcação comercial, embora sem caráter mandatório. Esse documento prevê uma série de medidas que podem ser adotadas para reduzir a emissão de ruídos nos oceanos, a exemplo da medição dos níveis de ruídos emitidos pelas embarcações, da realização de alterações no design dos navios, da substituição de peças e de maquinário, da limpeza adequada das hélices, da redução da velocidade das embarcações e da adoção de outras rotas, de modo a evitar que a embarcação navegue em áreas sensíveis, vulneráveis ou especialmente protegidas.

Muitos outros instrumentos internacionais existem, com aptidão para regular o problema da poluição sonora marinha, inclusive em âmbito regional. Como se vê, a ausência de normatização global, específica e cogente dessa espécie de poluição não significa que inexistam normas jurídicas aplicáveis à matéria.

Mesmo que se excluísse a poluição sonora do conceito de poluição marinha previsto na CNUDM - o que não parece admissível, dado o claro preenchimento dos requisitos do art. $1^{\circ}$ desse tratado -, a hipótese de vácuo normativo resta afastada, diante da pluralidade de instrumentos jurídicos que, embora não dedicados especificamente à regulação da poluição marinha, podem vir a ser-lhe aplicáveis.

\section{CONCLUSÃO}

A emissão de ruídos antropogênicos nos oceanos é um exemplo de introdução humana de energia no meio marinho e pode provocar danos aos recursos vivos e à vida marinha. De fato, verificou-se que ruídos artificiais nos oceanos podem prejudicar seriamente a fauna marinha, causando, por exemplo, mascaramento auditivo, danos e traumas acústicos a nível morfológico e celular, mudança de comportamento individual ou 
social, alteração do metabolismo corporal, emigração induzida (migração horizontal e vertical), desbalanceamento da relação presa-predador, desequilíbrios populacionais regionais, alterações na distribuição populacional marinha e redução na abundância de espécies marinhas, dentre tantas outras alterações nocivas.

Parece claro, assim, que é possível qualificar a emissão antropogênica de ruídos nos oceanos como uma espécie de poluição marinha, nos termos da definição trazida pelo art. $1^{\circ}$ da CNUDM, porque preenchidos os dois requisitos nela previstos.

Essa constatação tem relevância prática no que diz respeito ao tratamento jurídico dispensado à introdução humana de sons nos oceanos. Sendo espécie do gênero poluição marinha, a poluição sonora é abrangida por todas as disposições da CNUDM que disciplinam a poluição do meio marinho, o que afasta a possibilidade de existir um vácuo normativo quanto ao problema.

Afora a CNUDM, existem outros instrumentos globais e regionais que podem fornecer bases jurídico-normativas para a proteção do meio ambiente marinho, no que diz respeito à emissão antropogênica de ruídos nos oceanos, ainda que sem relacioná-la especificamente à definição de poluição marinha contida no art. $1^{\circ}$ da Convenção de Montego Bay.

Exemplos desses instrumentos são a Convenção Internacional para a Regulamentação da Pesca da Baleia, a Convenção sobre Diversidade Biológica, o Acordo para Implementação das Disposições da CNUDM sobre a Conservação e Ordenamento de Populações de Peixes Transzonais e de Populações de Peixes Altamente Migratórios, a Convenção de Bonn sobre Conservação de Espécies Migratórias de Animais Selvagens e até, talvez, a MARPOL, além das normatizações produzidas pela própria IMO.

Essa constatação leva a crer que, se o problema da poluição sonora nos oceanos persiste - e tem se tornado inclusive mais grave -, isso não se deve exatamente a um vazio normativo do ponto de vista do Direito Internacional, mas a outros fatores, como, talvez, a falta de vontade política na implementação de tratados internacionais, a prevalência de interesses econômicos em detrimento das normas de proteção ambiental, ou mesmo a dificuldade de fiscalização do cumprimento das exigências normativas de proteção acústica do meio ambiente marinho, o que abre novas frentes de pesquisa e faz brotar novas linhas de investigação e novos problemas jurídicos, a serem enfrentados pela Academia. 


\section{REFERÊNCIAS}

ASSEMBLEIA GERAL DA ORGANIZAÇÃO DAS NAÇÕES UNIDAS. Resolução $n^{\circ} 70$, de 21 de outubro de 2015: Transforming our world: the 2030 Agenda for Sustainable Development. Disponível em: $<$ http://www. un.org/ga/search/view_doc.asp?symbol=A/RES/70/1\&Lang=E>. Acesso em: 02 jul. 2017.

CERCHIO, Salvatore et al. Seismic Surveys Negatively Affect Humpback Whale Singing Activity off Northern Angola. Plos One, [s.1.], v. 9, n. 3, e86464, 11 mar. 2014.

CONCHA-BARRIENTOS, M., CAMPBELL-LENDRUM, D.; STEENLAND, K. Occupational noise: assessing the burden of disease from work-related hearing Impairment at national and local levels. 9. ed. Genebra: Organização Mundial da Saúde, 2004.

CORTEINTERNACIONALDEJUSTIÇA. Estatuto da Corte Internacional de Justiça. Disponível em: <http://www.icj-cij.org/en/statute>. Acesso em: 05 jul. 2017.

CRETELLA NETO, José. Curso de direito internacional do meio ambiente. São Paulo: Saraiva, 2012, p. 229.

DOTINGA, Harm M.; ELFERINK, Alex G. Oude. Acoustic pollution in the oceans: the search for legal standards. Ocean Development \& International Law, v. 31, n. 1-2, p. 151-182, 2000. Disponível em: < http://www. tandfonline.com/doi/pdf/10.1080/009083200276102?needAccess $=$ true $>$. Acesso em: 04 jul. 2017.

ELFERINK, Alex. G. Oude. Environmental impact assessment in areas beyond national jurisdiction. The International Journal of Marine and Coastal Law, v. 27, n. 2, p. 449-480, 2012. Disponível em: $<$ http://booksandjournals.brillonline.com/content/journals/10.1163/ 157180812x636598>. Acesso em: 08 jun. 2017.

ERBE, Christine et al. Communication masking in marine mammals: A review and research strategy. Marine Pollution Bulletin, [s.1.], v. 103, n. 1-2, p.15-38, fev. 2016.

FIRESTONE, Jeremy; JARVIS, Christina. Response and responsibility: 
regulating noise pollution in the marine environment. Journal of International Wildlife Law and Policy, v. 10, n. 2, p. 109-152, May 2007. Disponível em: < http://www.tandfonline.com/doi/full/10.1080/13880290 701347408>. Acesso em: 02 jul. 2017.

FOOD AND AGRICULTURE ORGANIZATION (FAO). Common oceans facts: marine areas beyond national jurisdiction (ABNJ). Disponível em: $\quad<$ http://www.fao.org/fileadmin/user_upload/common_oceans/docs/ i7381en.pdf>. Acesso em: 07 jul. 2017.

GILLESPIE, Alexander. The Precautionary Principle in the TwentyFirst Century: A Case Study of Noise Pollution in the Ocean. The International Journal of Marine and Coastal Law, v. 22, n. 1, p. 61-87, 2007. Disponível em: <http://booksandjournals.brillonline.com/content/ journals/10.1163/157180807781475227>. Acesso em: 29 jun. 2017.

GJERDE, Kristina M. Challenges to protecting the marine environment beyond national jurisdiction. The International Journal of Marine and Coastal Law, Leiden, v. 27, n. 4, p. 839-847, 2012. Disponível em: < http:// booksandjournals.brillonline.com/content/journals/10.1163/1571808512341255>. Acesso em: 11 jun. 2017.

HAWKINS, Anthony D.; PEMBROKE, Ann E.; POPPER, Arthur N.. Information gaps in understanding the effects of noise on fishes and invertebrates. Reviews In Fish Biology And Fisheries, [s.1.], v. 25, n. 1,

Artigo recebido em: 27/10/2017. Artigo aceito em: 25/05/2018.

\section{Como citar este artigo (ABNT):}

PRIMO, D. A. S.; BARRETO, C. P.; MONT'ALVERNE, T. C. F. DIREITO INTERNACIONAL E POLUIÇÃO SONORA MARINHA: EFEITOS JURÍDICOS DO RECONHECIMENTO DO SOM COMO FONTE DE POLUIÇÃO DOS OCEANOS. Veredas do Direito, Belo Horizonte, v. 15, n. 32, p. 277-295, ma./ago. 2018. Disponível em: $<$ http:// www.domhelder.edu.br/revista/index.php/veredas/article/view/1194>. Acesso em: dia mês. ano. 